\title{
Effect of grinding of hay on rumen particle kinetics in sheep
}

\author{
L Bernard, JP Chaise, C Poncet
}

INRA de Theix, laboratoire de la Dynamique de la digestion, 63122 Saint-Genès-Champanelle, France

Grinding of hay has been found to have variable effects on rumen mean retention time (MRT). The aim of the present work was to clarify this point by studying components of MRT and underlying mechanisms.

Four mature Texel wethers fitted with rumen and duodenal cannulae were fed a mixture of a chopped and a ground (8-mm screen) and pelleted orchard-grass hay $(2.4 \% \mathrm{~N}, 59.4 \% \mathrm{NDF})$ in the ratios $(90: 10,50: 50,30: 70$ or $10: 90)$ according to a $4 \times 4$ latin-square design. Food (1 $200 \mathrm{~g} / \mathrm{d}$ ) was delivered in 8 equal meals. The amount of DM and indigestible acid detergent lignin (IADL) contents and size distribution of rumen particles were determined by emptying and wet-sieving. Duodenal digesta were analyzed in the same manner and their flows were estimated using the double-marker technique $\left({ }^{169} \mathrm{Yb}\right.$ acetate and ${ }^{51} \mathrm{Cr}$-EDTA).
Particle MRT in the rumen estimated with $I A D L$ decreased and then plateaued when the proportion of ground hay in the diet was increased. The comminution rate of large particles (LP) was always higher than the small particle (SP) outflow rate, indicating that comminution is not the limiting step of passage. These results were the consequence of the curvilinear and opposite evolutions of the particulate DM pool in and outflow from the rumen (table I). Passage rate variations could not be explained by aperture number of the reticulo-omasal orifice.

In conclusion, the curvilinear effect of grinding grass hay at the same level of intake on components of MRT (pools and flow) may explain the discrepancy between published results in this field.

Table I. Particle kinetics in the rumen as affected by grinding a grass hay.

\begin{tabular}{|c|c|c|c|c|c|}
\hline Chopped / Ground hay & & $90: 10$ & $50: 50$ & $30: 70$ & $10: 90$ \\
\hline \multirow[t]{3}{*}{ Rumen DM pool $(g)$} & Total & $1123^{a}$ & $851^{\mathrm{b}}$ & $840^{\mathrm{b}}$ & $858^{b}$ \\
\hline & LP & $335^{a}$ & $174^{b}$ & $146^{\mathrm{b}}$ & $137^{b}$ \\
\hline & SP & $721^{a}$ & $602^{\mathrm{b}}$ & $626^{\circ}$ & $665^{\mathrm{ab}}$ \\
\hline \multirow[t]{2}{*}{ Duodenal DM flow $(\mathrm{g} / \mathrm{d})$} & Total & 808 & 888 & 833 & 826 \\
\hline & SP & $621^{b}$ & $715^{a}$ & $662^{a b}$ & $648^{b}$ \\
\hline IADL MRT (h) & & $42.2^{\mathrm{a}}$ & $28.0^{\mathrm{b}}$ & $31.5^{b}$ & $30.8^{b}$ \\
\hline LP comminution rate $\left(\% \cdot \mathrm{h}^{-1}\right)$ & & 6.4 & 7.1 & 7.2 & 5.5 \\
\hline SP Passage rate $\left(\% \cdot h^{-1}\right)$ & & $3.7^{\mathrm{d}}$ & $5.0^{\mathrm{a}}$ & $4.4^{b}$ & $4.1^{\mathrm{c}}$ \\
\hline
\end{tabular}

a, b, c $P<0.05$. 